\title{
Experiência interdisciplinar no ensino de biologia celular e desenho arquitetônico
}

\author{
Marcelo Alberto Elias \\ Instituto Federal do Paraná (IFPR) \\ (marcelo.elias@ifpr.edu.br) \\ Grasielle Cristina dos Santos Lembi Gorla \\ Instituto Federal do Paraná (IFPR) \\ (grasielle.gorla@ifpr.edu.br)
}

\begin{abstract}
Resumo: Atualmente, muitos são os desafios encontrados no processo de ensino e aprendizagem nas escolas, em especial nos cursos técnicos integrados ao ensino médio. Nesse panorama, a abordagem interdisciplinar pode vir em resposta a muitas frustrações metodológicas encontradas pelos docentes em seu cotidiano escolar. Partindo desse pressuposto, o presente trabalho buscou investigar a colaboração da interdisciplinaridade em uma turma de segundo ano do Curso Técnico em Edificações Integrado ao Ensino Médio, do Instituto Federal do Paraná (IFPR), campus Umuarama, PR. Participaram da pesquisa trinta e seis discentes, que tinham o desafio de praticar uma atividade integradora entre os componentes curriculares de Biologia e Desenho Arquitetônico II, em um bimestre letivo. A proposta interdisciplinar consistia em elaborar um projeto arquitetônico desenvolvido apenas até o nível de planta baixa - que utilizasse como referência a morfologia e composição de um tipo celular, sorteado a cada estudante. Deste modo, todos os alunos possuiriam um modelo distinto para usar como inspiração projetiva. Ao final, os resultados foram analisados de maneira qualitativa (a partir do discurso dos estudantes durante o processo e da apresentação gráfica dos projetos) e apontaram que a interdisciplinaridade colaborou com o sistema educacional, trazendo mais qualidade e dinamismo ao processo de ensino e aprendizagem.
\end{abstract}

Palavras-chave: Ensino de biologia; Educação profissional; Metodologia de ensino,

\section{Interdisciplinary experience in teaching cell biology and architectural design}

Abstract: Currently, there are many challenges encountered in the teaching and learning process in schools, especially in technical courses integrated to high school. In this context, the interdisciplinary approach may come in response to many methodological frustrations encountered by teachers in their school routine. Basedon this assumption, the present research sought to investigate the collaboration of interdisciplinarity in a second-year class of the Technical Course in Buildings Integrated to High School, from the Federal Institute of Paraná (IFPR), Umuarama campus, Pr. Thirty-six students participated in the research, who had the challenge of practicing an integrating activity between the curricular components of Biology and Architectural Design II, in an academic term. The interdisciplinary proposal consisted of elaborating an architectural project - developed only at the level of a floor plan - using as reference the morphology and composition of a cell type, drawn for each student. In this way, all students would have a different model to use as a projective inspiration. In the end, the results were analyzed in a qualitative from the students' discourse throughout the process way and pointed out that interdisciplinarity can significantly collaborate with the educational system, bringing more quality and dynamism to the teaching and learning process.

Keywords: Biology teaching; Professional education; Teaching methodology,

\section{INTRODUÇÃO}

O aprendizado tem como finalidade proporcionar ao educando uma melhor compreensão de mundo, permitindo conhecimentos generalizados para que ele consiga realizar escolhas sensatas e coerentes, além de assegurar-Ihe consciência 
em relação às suas atitudes e condutas. Nesta acepção, a escola tem um papel muito importante no contexto social, sendo a grande responsável pela divulgação científica de diversas especialidades (SILVA; FERREIRA; VIERA, 2017).

No entanto, muitos são os desafios atuais instaurados para a consolidação do processo educativo. Sabe-se, que além das questões pedagógicas, influenciam essa relação os fatores sociais, econômicos, emocionais e, até mesmo, os biológicos. Deste modo, pensar em estratégias que enriqueçam a metodologia didática é fundamental na atualidade e, neste sentido, a abordagem interdisciplinar - como proposta de revisão do pensamento positivista na educação - vem de encontro a este fim, se mostrando como uma grande influenciadora das concepções contemporâneas que tratam do processo de ensino e aprendizagem (ALARÇÃO, 2008; THIESEN, 2008; THIESEN, 2013).

Em um mundo cada dia mais complexo, dinâmico e interconectado, as formas tradicionais de ensinar e aprender também precisam evoluir. Um sistema educacional baseado simplesmente na transmissão linear e fragmentada da informação, certamente não será mais suficiente. A escola precisa acompanhar o ritmo das mudanças que se permeiam em todos os segmentos sociais. É preciso que ela e seu corpo docente adotem um novo formato de ensino, que possibilite uma maior integração das diferentes áreas do conhecimento, tanto no aspecto conceitual, como metodológico. Por isso, o movimento da interdisciplinaridade está sendo considerado como uma condição primordial para o ensino e pesquisa na sociedade vigente, almejando romper com a conduta disciplinar, parcelada e dogmatizada que, por muito tempo, assinalou a concepção cartesiana de mundo (THIESEN, 2013).

Formulada como proposta proeminente e assumida enquanto ação coletiva, a interdisciplinaridade tem o potencial de colaborar com docentes e regime escolar na busca por um novo significado do trabalho didático/pedagógico em termos de método, adequação de currículo, formas de avaliação e organização espacial mais adequada ao processo de ensino e aprendizagem (THIESEN, 2008). Um processo educativo sob a conduta interdisciplinar aproxima diferentes áreas do saber em prol de objetivos bem definidos, como:

- Auxiliar os alunos na compreensão das complexas redes conceituais (THIESEN, 2008). 
Experiência interdisciplinar no ensino de biologia celular e desenho arquitetônico

- Contribuir para uma melhor assimilação dos conteúdos de aprendizagem, estabelecendo uma relação clara entre teoria e prática (THIESEN, 2008).

- Motivar uma maior participação estudantil nas aulas e atividades escolares, promovendo, inclusive, uma maior socialização entre tais alunos (LAGO; ARAÚJO; SILVA, 2015).

- Proporcionar um conhecimento aplicável ao contexto sociocultural, em que o aluno identifique relação entre o conteúdo ministrado em sala de aula e a sua aplicabilidade em situações do cotidiano (LAGO; ARAÚJO; SILVA, 2015).

- Permitir uma formação mais consistente e crítica (THIESEN, 2008).

Através de uma ação coordenada, a interdisciplinaridade pode ser proposta, basicamente, sob dois enfoques: a partir de uma abordagem que ressalte a assimilação do processo de produção do conhecimento; ou mediante a proposta de um tema gerador único, que possa ser trabalhado pelas distintas unidades curriculares envolvidas no sistema. Uma das possibilidades de trabalho a partir da interdisciplinaridade é através da realização de projetos em conjunto, por meio dos quais, os docentes introduzem o estudo de conteúdos que não são exclusivos de nenhum componente curricular, mas que englobam duas ou mais unidades (LAGO; ARAÚJO; SILVA, 2015).

De uma forma geral, é na área das ciências humanas e sociais que o movimento da interdisciplinaridade ganha mais expressividade. A preocupação com uma visão mais global da realidade que pode ser conhecida, bem como a maior integração das ciências foi fruto de estudo, inicialmente, pelo segmento da filosofia, depois passou para as ciências sociais e encontra-se mais recentemente no foco da epistemologia pedagógica (THIESEN, 2008).

No caso específico do ensino de Biologia em cursos técnicos profissionalizantes (cuja área de atuação não está vinculada à de ciências biológicas) é preciso repensar o processo educativo, já que muitas vezes, ele se torna cansativo e desmotivador aos estudantes. Isso em virtude dos mesmos, geralmente, se dedicarem mais ao estudo de componentes curriculares que os aproximam das habilidades exigidas pela futura formação (ALARCÃO, 2008). 
Mas independente desse contexto, autores como Silva, Ferreira e Vieira (2017) ressaltam que o ensino de Ciências e Biologia é fundamental para a implantação do método científico na sociedade. Nesta relação, o professor é o mediador da transmissão de conhecimento, o qual capacita o discente na compreensão geral do mundo e dos seres que nele habitam. Por meio deste entendimento, o aluno é apto a tornar-se um indivíduo pensante e crítico diante da realidade.

Em um curso de ensino médio, no qual além da abordagem de conteúdo tradicional há uma prerrogativa de formação profissionalizante, é comum o discente voltar-se aos componentes mais relacionados com a área da futura atuação. Dentro desse panorama, metodologias diversificadas e integradoras são uma boa alternativa, pois relacionam atividades que englobam mais de uma frente de conhecimento, e neste sentido, permitem enriquecer a pluralidade conceitual (SOARES; DINIZ, 2009).

Na mesma linha de raciocínio, Alarcão (2008) ainda ressalta que quanto mais interdisciplinar for a dinâmica do conceito exposto, maior será a possibilidade de abstração do mesmo. Em especial, em cursos técnicos integrados, onde os estudantes estão recebendo uma formação profissional além da básica.

Em meio a esta realidade, os autores deste trabalho, realizaram uma experiência interdisciplinar entre dois componentes curriculares do Curso Técnico em Edificações Integrado ao Ensino Médio: Biologia e Desenho Arquitetônico (nível II). A turma escolhida foi a do segundo ano, em razão do ensino de biologia celular se concentrar nesta série. O outro componente participante da integração está presente em todos os quatro anos do curso, sempre em nível equivalente à respectiva série. Em anos iniciais, tal disciplina volta-se às práticas de Desenho Técnico e assimilação de convenções do Desenho Arquitetônico, bem como a realização de concepções projetivas de baixa complexidade. À medida que o curso avança, o componente Desenho Arquitetônico engloba um grau maior de detalhamento técnico e suas composições vão sendo enriquecidas com um nível de complexidade que cada vez mais é demandado pelo segmento da construção civil.

O desenho técnico está presente em uma gama de especialidades e tem como objetivo representar objetos tridimensionais sobre superfícies planas, por meio de uma relação proporcional, chamada escala. Essas representações possibilitam 
que o projetista apresente as características relacionadas às formas e dimensões do objeto, fazendo com que seja possível a compreensão global do elemento. Neste sistema, existem dois métodos projetivos: as projeções ortogonais e as perspectivas (PEREIRA, 2012). A projeção ortogonal é uma representação que mostra apenas um lado do objeto, exibindo um aspecto específico dele, como sua aparência frontal (elevação); ou o traçado e dimensões de largura e profundidade de um espaço (no caso de uma planta baixa).

A planta baixa corresponde ao principal desenho de um projeto arquitetônico, que é uma ramificação do desenho técnico, e como tal, segue normas e convenções técnicas de representação - só que neste caso, relacionadas ao universo linguístico da construção civil. Ela corresponde a uma vista área da edificação, como se existisse um corte horizontal imaginário - paralelo ao chão em 1,50 m - e que, a partir dele, toda a parte superior da edificação fosse removida, permitindo visualização interna. Com este procedimento, é possível identificar as principais características bidimensionais do projeto arquitetônico, como o formato e o dimensionamento dos ambientes, o padrão de portas e janelas, os elementos fixos das áreas molhadas, as escadas e fluxos circulatórios, bem como a espessura e a localização das paredes (KUBBA, 2014).

Diante do contexto exposto, a atividade interdisciplinar praticada neste trabalho, teve como propósito unir duas unidades curriculares bem distintas - uma de formação básica de educação e outra, profissionalizante - para que o aluno pudesse perceber a relevância do conhecimento formal, mesmo em um curso que tem como foco um exercício profissional específico.

\section{METODOLOGIA}

A pesquisa realizada foi de natureza aplicada, com abordagem metodológica qualitativa e objetivo descritivo (MINAYO; DESLANDES; GOMES, 2011).

Para tal proposta, optou-se pela turma de segunda série do Curso Técnico em Edificações Integrado ao Ensino Médio do Instituto Federal do Paraná (IFPR), campus Umuarama, por ela abranger o conteúdo programático do ensino de biologia celular. O projeto integrou dois componentes curriculares, um pertencente ao núcleo básico de formação - Biologia - e outro, relacionado à proposta profissionalizante do 
curso - Desenho Arquitetônico II. A atividade foi executada em formato presencial, predominantemente, em horário regular de aula, durante o segundo bimestre do ano letivo de 2019, entre os meses de abril e julho. Participaram da pesquisa os trinta e seis discentes matriculados no curso, com faixa etária entre 16 e 17 anos.

Inicialmente, os discentes foram orientados a respeito do trabalho bimestral que iriam desenvolver, em uma aula ministrada pelos dois professores dos respectivos componentes, cada qual explanando sobre suas expectativas em relação ao desenvolvimento e entrega da atividade. Logo após, a realização de um sorteio permitiu que cada aluno, individualmente, conhecesse a denominação do tipo celular com o qual iria trabalhar. Todas as células sorteadas foram escolhidas de acordo com sua forma e função descritas por Junqueira e Carneiro (2013).

A partir de então, as aulas de Biologia tiveram abordagem com consideração às células sorteadas, em uma mescla didática que incluía explicação do docente e pesquisa acadêmica individual e aprofundada sobre os dados de cada modelo. Neste processo, o aluno deveria explorar a composição e morfologia do tipo celular e até poderia usar seus mecanismos de atuação no corpo humano para incrementar a elaboração projetiva. Visando facilitar a criação do projeto, o aluno deveria escolher uma imagem bem característica da célula para servir de referência.

Após a etapa de apresentação e pesquisa sobre o modelo celular, cada discente deveria conceber a planta baixa de um projeto arquitetônico residencial, embasado nas principais características e morfologia da sua célula. Neste processo, ele deveria ser fiel ao aspecto celular, mas poderia extrapolar em criatividade. A edificação térrea deveria abranger uma área total de até $220 \mathrm{~m}^{2}$, com implantação em um terreno de dimensões livres. O programa de necessidades compunha-se dos seguintes elementos:

- Garagem para automóveis (com uma ou duas vagas, a critério do aluno);

- 1 sala de estar/TV;

- 1 sala de jantar;

- 1 cozinha;

- 1 suíte;

- 1 banheiro íntimo;

- 2 quartos;

- 1 banheiro social; 
- 1 lavanderia;

- 1 área de churrasco;

- 1 lavabo.

O início do desenvolvimento do projeto deveria ser antecipado pelo processo de fluxograma (um tipo de diagrama que orienta a relação espacial do programa de necessidades) e croquis de elaboração (que caracterizam esboços manuais, sem a utilização de instrumentos e normas de desenho, visando a concepção embrionária do projeto e o esquema das principais ideias do partido arquitetônico). Após a realização de tais processos e do aval docente, o aluno estaria apto a desenvolver o projeto propriamente dito, por meio de normativas de representação técnica.

De modo geral, a representação gráfica pode ser manual - quando é desenvolvida por meio de prancheta, papéis e instrumentos específicos - como também através de ferramentas digitais, que são capazes de agilizar e dar maior precisão ao processo. Neste projeto integrador, optou-se por utilizar o software AutoCAD, versão 2018. Cada aluno desenvolvia seu projeto individualmente, em horário regular da unidade Desenho Arquitetônico II. A docente responsável pelo componente procedia com atendimentos individualizados de orientação, conforme a necessidade de cada aluno. Em alguns casos, houve a necessidade de atendimentos extraclasses, para que os alunos que apresentassem maior dificuldade na elaboração projetiva tivessem um tempo maior para o desenvolvimento do trabalho.

No momento da entrega do projeto, além de um desenho legível - que correspondesse às expectativas e normativas do trabalho - 0 aluno precisava expor suas ideias na gênese projetiva, deixando claro o modo como se fundamentou na morfologia ou função do respectivo tipo celular para a criação arquitetônica. Os registros qualitativos foram realizados durante toda a pesquisa, através da observação dos discursos dos estudantes na atividade e também da análise conceptiva do projeto apresentado. Cabe ressaltar que a avaliação de uma concepção arquitetônica possui caráter subjetivo, por se tratar de algo que envolve diversas variáveis, como estilo arquitetônico vigente, aspectos sócio-econômicos, aspectos culturais, fatores relacionados com sustentabilidade, acessibilidade, legislação, etc. Por isso, esta análise pode variar de acordo com o indivíduo que a realiza. 
No final da atividade, foi realizada uma avaliação com base em referenciais teóricos que abordam a interdisciplinaridade como prática pedagógica. As etapas metodológicas estão resumidas no fluxograma da figura 1.

Figura 1 - Fluxograma das etapas metodológicas.
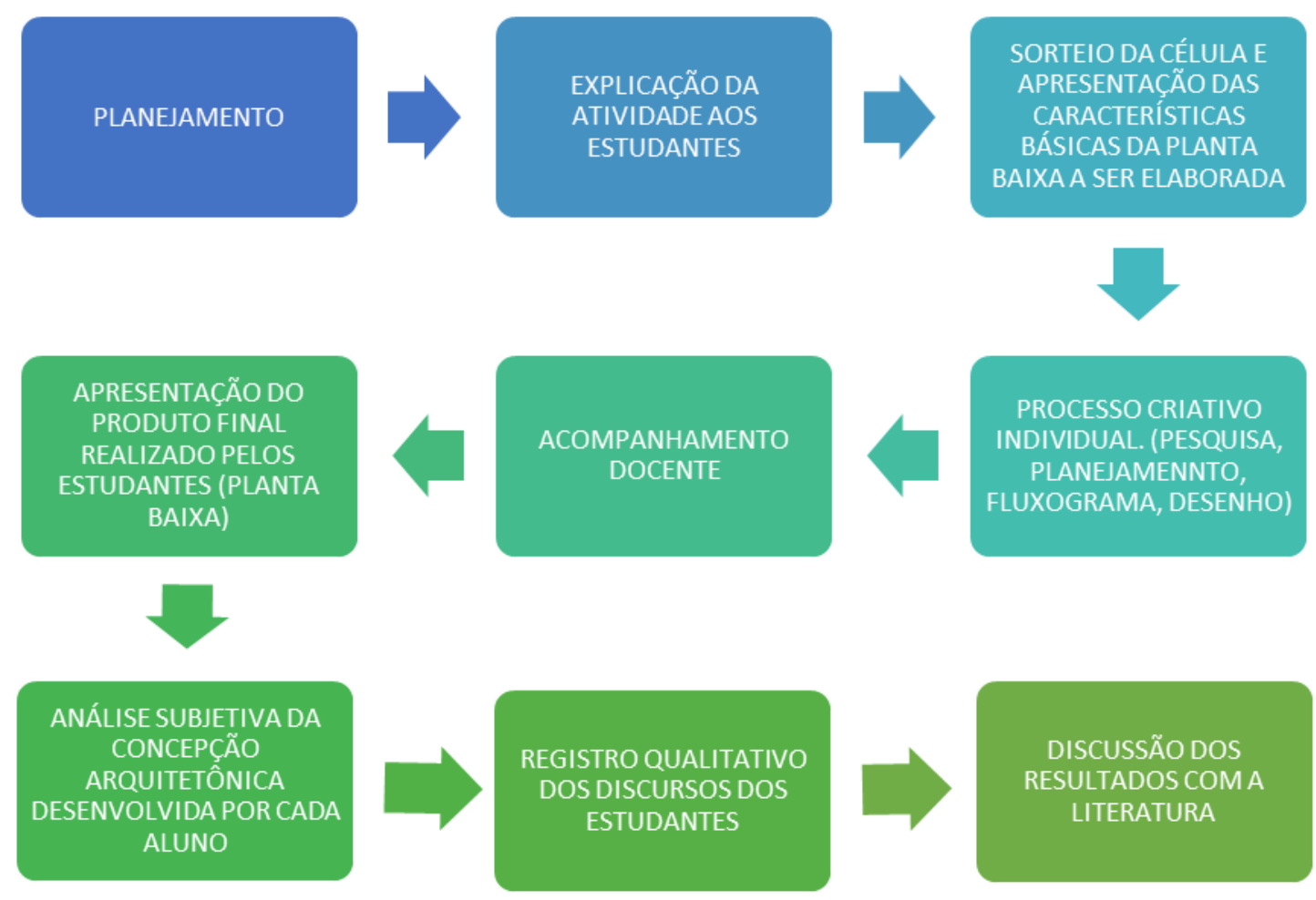

Fonte: Autores

\section{RESULTADOS E DISCUSSÃO}

Essa atividade interdisciplinar uniu dois componentes curriculares de tipos distintos: um pertencente ao núcleo básico de ensino (Biologia) e outro de caráter mais específico (Desenho Arquitetônico II), voltado à área de edificações. Por meio dela, foi possível ultrapassar a fronteira artificial do conteúdo desmembrado e construir um conhecimento mais amplo e significativo, no qual a abordagem de biologia se interligou a uma área técnica, bem representativa do curso.

Nesta acepção, o ensino de biologia ultrapassou os mecanismos da simples memorização de conceitos científicos, permeando para uma experiência mais aplicável à área de atuação do respectivo curso. Silva, Ferreira e Vieira (2017) 
afirmam em seus estudos, que essa extrapolação no processo de ensino e aprendizagem é urgente para o cotidiano escolar atual.

Apesar de tais unidades curriculares terem focos didáticos totalmente diferentes, nesta experiência coordenada, se uniram em prol de um objetivo comum: construir um conhecimento mais consolidado, no qual o aluno tem a oportunidade de assimilar a importância de todos os conteúdos abordados ao longo do curso, sejam eles pertencentes ao núcleo específico de atuação ou não. Segundo Alarcão (2017), a união de interesses pedagógicos fortalece a interdisciplinaridade.

Além disso, um dos objetivos da ação interdisciplinar é estimular uma maior participação estudantil em atividades de ensino e aprendizagem. $E$ isso foi verificado neste trabalho: os docentes perceberam que os alunos se sentiram mais motivados em relação à abordagem dessas duas unidades didáticas ao longo do período da atividade coletiva. Tal aspecto foi evidenciado tanto pela assiduidade dos alunos, como pelo grande envolvimento no projeto. Esse resultado é reforçado por Alarcão (2017) e Thiesen (2013), em seus respectivos estudos, afirmando que em ações interdisciplinares o envolvimento do estudante acontece de maneira extremamente ativa.

Ao final do processo, todos os estudantes conseguiram desenvolver e concluir as atividades propostas. Apresentam-se a seguir, exemplos de dois modelos celulares nas suas respectivas versões de concepção arquitetônica: primeiro é apresentado a planta baixa de uma residência inspirada na morfologia celular de uma célula muscular esquelética - que tem a função primordial de contração e movimento -; depois há uma proposta arquitetônica do tipo celular ovócito, que é o gameta feminino com função reprodutiva (figuras 2-A e 2-B). 
Experiência interdisciplinar no ensino de biologia celular e desenho arquitetônico

Figura 2 - Exemplos de plantas baixas desenvolvidas pelos estudantes como propostas arquitetônicas (A - Célula Muscular esquelética e B - Ovócito)
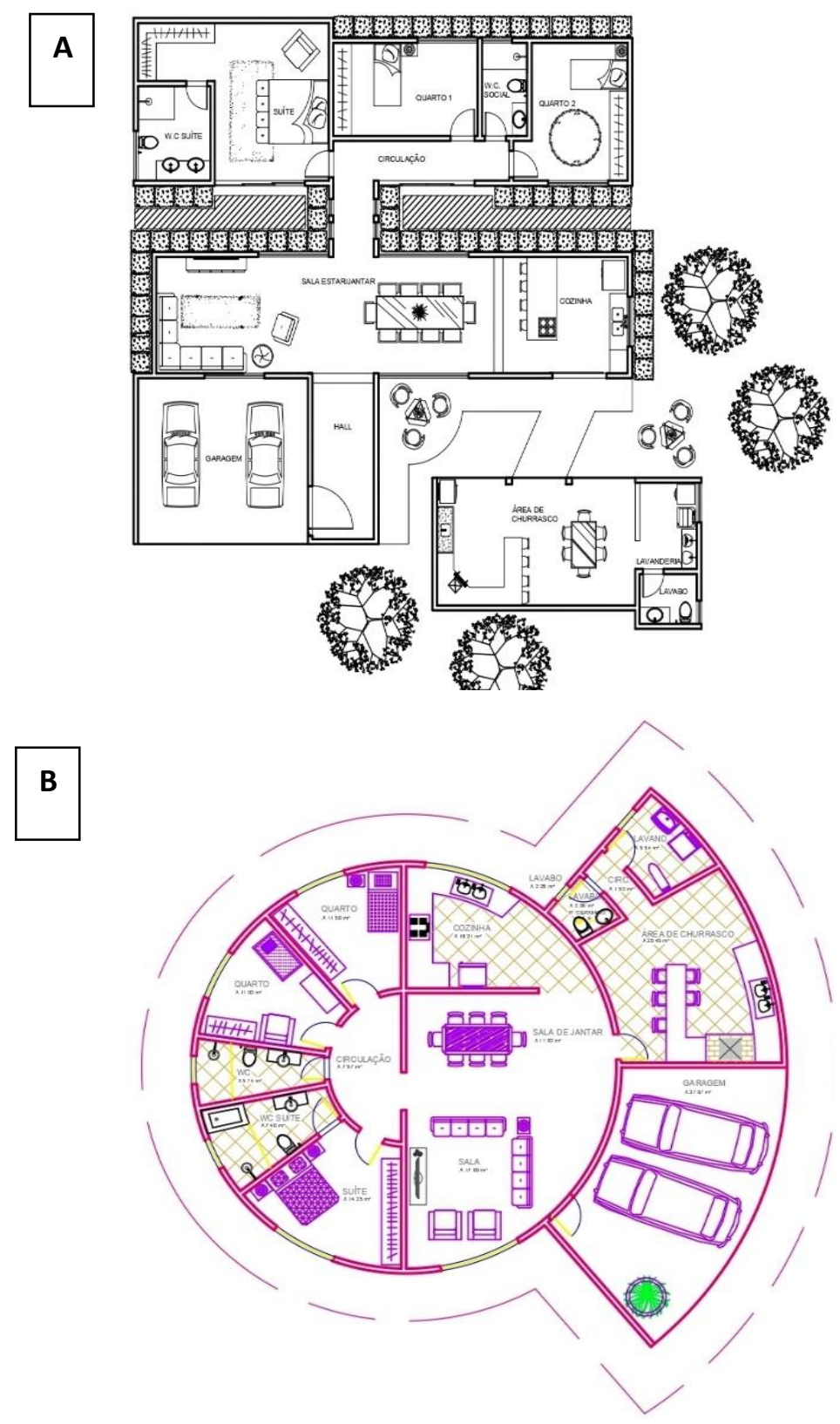

Fonte: Autores

A avaliação final comprovou que este trabalho interdisciplinar beneficiou 0 ensino de Biologia, dentro de um curso de edificações. No bimestre considerado, quase $90 \%$ dos alunos obteve um conceito equivalente a aprendizagem plena ou parcialmente plena. Esse percentual - quando comparado a outros bimestres letivos - é bastante expressivo, uma vez que outrora, o percentual foi de $70 \%$. Esses resultados vão de encontro com as afirmações de Thiesen (2013), que aponta a 
característica articuladora da integração como um fator de melhoria na abstração, e consequentemente, no rendimento dos escolares.

Quanto ao componente Desenho Arquitetônico II, o resultado também se mostrou bem promissor, com a concepção de projetos interessantes, de acordo com o julgamento da docente responsável - ainda mais por se tratar de uma turma que, relativamente, está no início do curso. É claro que esta é uma análise de cunho subjetivo, já que em arquitetura, as avaliações conceptivas envolvem uma série de variáveis. Quando se analisa uma obra arquitetônica, um dos primeiros requisitos é verificar se ela atende aos parâmetros instituídos pela tríade vitruviana: Firmitas (solidez), Utilitas (utilidade) e Venustas (beleza) (PEREIRA, 2010).

No caso específico desta atividade, o projeto deveria atender, além dos requisitos impostos pelo programa de necessidades (correspondentes à função da obra) às dimensões estéticas, seguindo a morfologia da célula sorteada para o trabalho. Mesmo que esta forma não fosse tão convencional à tipologia arquitetônica estabelecida (uma residência térrea), tal projeto precisava ser coerente com os aspectos estruturais, possibilitando a sua construção efetiva (e não simplesmente ser fruto de uma proposta fantasiosa, impossível de ser concretizada).

Considerando estes aspectos, a docente classificou que a grande maioria dos alunos conseguiu elaborar um projeto de qualidade sob a influência da respectiva célula. Além disso, a maioria dos projetos considerou a legislação pertinente em sua composição, bem como aspectos relacionados à acessibilidade, sustentabilidade, questões culturais, etc.

Com a indicação desses resultados satisfatórios, fica bastante sugestivo o papel positivo da interdisciplinaridade entre unidades curriculares distintas, sinalizando uma direção frutífera no ensino de curso integrado. Esse direcionamento metodológico satisfatório é sugerido também pelos autores Silva, Ferreira e Vieira (2017), que apontam a mesma como transformadora do processo de ensino e aprendizagem.

Apesar do tema "interdisciplinaridade" estar em pauta em muitas instituições de ensino, os desafios dessa inovação metodológica para superar um ensino individualizado que a conduta convencional estabelece, ainda são grandes. Um deles está na própria formação que os docentes recebem, a qual, muitas vezes, não os encoraja a praticar a integração didática no cotidiano de suas escolas. Uma boa 
alternativa, seria uma mudança significativa no processo formativo dos novos professores, bem como um sistema permanente de capacitação para aqueles já atuantes, os motivando a adotar posturas que vão além do mero cumprimento da sua carga de conteúdos programáticos.

Outra sugestão seria a realização de reuniões periódicas entre professores e pedagogos, com o intuito de apresentar - mesmo que de forma sintetizada e abrangente - o conteúdo de cada unidade da grade curricular do curso, bem como a prática didática de cada professor. Com a exposição das intenções metodológicas de cada integrante do corpo docente é mais fácil pensar em ações conjuntas, capazes de englobar dois ou mais componentes em atividades interdisciplinares, que estejam em sintonia aos interesses da área de atuação do curso.

Essa dinâmica pode contribuir para o desapego da postura individual de cada docente (envolto apenas na relevância do seu conteúdo) para promover uma metodologia mais integrada, na qual a abordagem coletiva favorece um ensino mais estimulante e voltado à necessidade profissional. Assim, a transmissão do conhecimento de uma determinada área não perderá seu caráter de especialidade, mas será reconstruída por métodos e processos mais produtivos e que confiram maior significado aplicável à realidade do aluno (ALARCÃO, 2017; THIESEN, 2013).

Adotando tais práticas, é provável que os docentes (assim como os envolvidos nessa pesquisa) se sintam mais aptos e seguros a atuarem em coletividade, estabelecendo ligação didática entre os componentes curriculares de seus cursos.

\section{CONSIDERAÇÕES FINAIS}

A interdisciplinaridade é uma necessidade emergente na educação contemporânea, a fim de transpor a divisão individualista e fragmentada do ensino tradicional. Ela é uma ferramenta valiosa de articulação do processo de ensino e aprendizagem em qualquer contexto escolar e entre qualquer tipo de componente curricular, em especial quando é instaurada em um curso que, além da abordagem convencional, propõem uma formação técnica. Isso porque, em um curso profissionalizante, geralmente o foco do discente é nos componentes curriculares relacionados à área de atuação, relegando a segundo plano, as unidades didáticas 
do núcleo básico. Neste caso, o uso de metodologias integradas torna o ensino mais atrativo e próximo da realidade profissional que o aluno enfrentará; por isso o estimula a se interessar por todos os componentes - mesmo aqueles que não são exclusivamente da área profissional a que o curso se destina.

Neste contexto, o presente trabalho mostrou resultados promissores em relação à interdisciplinaridade de dois componentes curriculares distintos de um curso profissionalizante de ensino médio - um referente ao núcleo básico de educação (Biologia) e outro voltado à área técnica de Edificações (Desenho Arquitetônico). A proposta - que visava interligar o ensino de biologia celular à concepção arquitetônica de uma residência térrea - estimulou uma maior participação estudantil e ainda produziu ótimas propostas projetivas, além de intensificar o estudo de um tema científico (tipologia de células), que nem sempre é valorizado por alunos que almejam uma formação mais técnica, em um segmento distinto da área biológica.

Para a implementação de atividades interdisciplinares deste tipo, é necessária a intensificação do planejamento coletivo didático, bem como alterações no próprio processo formativo dos docentes, com metodologia diferenciada para os novos profissionais e um sistema de capacitação para os já atuantes. Nesta acepção, os professores certamente serão capazes de propor a inclusão da conduta interdisciplinar na metodologia didática da escola.

\section{REFERÊNCIAS}

ALARCÃO, I. Professores reflexivos em uma escola reflexiva. São Paulo: Cortez, 2008.

ALARCÃO, I. Entrevista. Revista Internacional de formação de professores. Itapetiniga. $\quad$ V. 2 n. 4 p. 156-165. $2017 . \quad$ Disponível em:<https://periodicos.itp.ifsp.edu.br/index.php/RIFP/article/view/1000/777>. Acesso em: 18 junho 2020.

KUBBA, S. A. A. Desenho Técnico para construção. Tradução: Alexandre Salvatera. Porto Alegre: Bookman, 2014.

JUNQUEIRA, LC; CARNEIRO, J. Histologia básica. 12. ed. Rio de Janeiro: Guanabara Koogan, 2013. 
LAGO, W. L. A.; ARAÚJO, J. M.; SILVA, L. B. Interdisciplinaridade e ensino de ciências: perspectivas e aspirações atuais do ensino. Saberes: Filosofia e Educação. Natal, vol.1 n.11 p. 52-63. 2015. Disponível em: <https://periodicos.ufrn.br/>. Acesso em: 16 abril 2020.

MINAYO, M. C. S.; DESLANDES, S. F.; GOMES, R. Pesquisa social: teoria, método e criatividade. 30. ed. Petrópolis: Vozes, 2011.

PEREIRA, José Ramón Alonso. Introdução à História da Arquitetura: das origens ao século XXI. Tradução: Alexandre Salvaterra. São Paulo: Bookman, 2010.

PEREIRA, N. C. Desenho Técnico. Curitiba: Livro Técnico, 2012.

SILVA, A. F.; FERREIRA, J. H.; VIERA, C. A. O ensino de ciências no ensino fundamental e médio: reflexões e perspectivas sobre a educação transformadora. Revista Exitus. Santarém/PA, vol. 7 n. 2 p. 283-304 Maio/Ago. 2017. Disponível em: <http://dx.doi.org/10.24065/2237-9460.2017v7n2ID314>. Acesso em: 01 abril 2020.

SOARES, M. N.; DINIZ, R. E. S. Educação problematizadora e teoria crítica: Contribuições freireanas e frankfurtianas para se pensar a função social do ensino de biologia. In: Encontro Nacional de Pesquisas em Educação em Ciências - VII Enpec. Florianópolis, 2009. Disponível em: <http:// http://www.posgrad.fae.ufmg.br/>. Acesso em: 10 abril 2020.

THIESEN, J. S. A interdisciplinaridade como um movimento articulador no processo ensino-aprendizagem. Rev. Bras. Educ. Rio de Janeiro, vol. 13 n. 39 Set./Dec. 2008. Disponível em: <https://doi.org/10.1590/S1413-24782008000300010 >. Acesso em: 20 abril 2020.

THIESEN, J. S. Currículo interdisciplinar: contradições, limites e possibilidades. Perspectiva. Florianópolis, vol. 31 n. 2 p.591 - 614Mai/Ago. 2013. Disponível em: $<$ https://periodicos.ufsc.br/index.php/perspectiva/article/view/2175795X.2013v31n2p591/26325>. Acesso em: 18 junho 2020. 